\title{
Detection of toxigenic Clostridium difficile in powdered infant and follow-up formulae in Egypt
}

\author{
Nagah Mohammed Saad ${ }^{1}$, Wallaa Farouk Amin $^{1}$ and Eman Mokhtar Shaker ${ }^{2}$ \\ 1. Department Food Hygiene, Faculty of Veterinary Medicine, Assiut University, Assiut, Egypt; 2. Department Food \\ Hygiene, Faculty of Veterinary Medicine, Sohag University, Sohag, Egypt \\ Corresponding author: Eman Mokhtar Shaker, email: milk 121970@yahoo.com \\ Received: 07-07-2013, Revised: 03-09-2013, Accepted: 03-09-2013, Published online: 01-10-2013
}

doi: $10.14202 /$ vetworld.2013.862-864

How to cite this article: Saad NM, Amin WF and Shaker EM (2013) Detection of toxigenic Clostridium difficile in powdered infant and follow-up formulae in Egypt, Veterinary World 6(11): 862-864.

\begin{abstract}
Aim: To examine powdered infant formula (PIF) and follow-up formula (FUF) for the presence of toxigenic Clostridium difficile.

Materials and Methods: A total of 100 random samples of PIF and FUF, 50 samples each, from various pharmacies and supermarkets located in Assiut city were collected during 2008-2010.

Results: Our results show that 16 out of $100(16 \%)$ examined samples of PIF and FUF were contaminated with $C$. difficile; 4 $(8 \%)$ and $12(24 \%)$ of the examined PIF and FUF samples tested positive for C. difficile, respectively. Only two (16.67\%) isolates of $C$. difficile from the examined FUF were toxigenic, while the isolates from the PIF samples were not toxigenic.

Conclusions: The presence of $C$. difficile in PIF and FUF samples suggests that there is a high potential for the transmission of C. difficile through these products. Thus, proper preparation and handling of these products is required to reduce the risk of the illnesses arising due to $C$. difficile.
\end{abstract}

Key words: Clostridium difficile, follow-up formula, latex agglutination, powdered infant formula, toxigenic

\section{Introduction}

Clostridium difficile is a spore-forming, obligate anaerobic, Gram positive bacillus and is usually acquired either from the environment or via the fecaloral route. In particular, the toxins $\mathrm{A}$ and $\mathrm{B}$ of $C$. difficile are responsible for causing intestinal disease. $C$. difficile is the most common cause of antimicrobialassociated diarrhea and is also a common health careassociated pathogen. Clinical symptoms vary widely, from asymptomatic colonization to pseudomembranous colitis with bloody diarrhea, fever, and severe abdominal pain [1]. Although the disease was first described in 1893, the etiologic agent was not isolated and identified until 1978 when the pseudomembranous colitis was first described as a complication of $C$. difficile infection [2]. In rare cases colitis can progress to toxic megacolon, which can be life-threatening and may lead to colonic perforation, sepsis and even death $[3,4]$.

Toxin expression is the major pathomechanism in C. difficile-associated diseases [5]. Toxin A acts as an enterotoxin leading to diarrhoea and inflammation of the colon; whereas toxin B produces cytotoxic effects via cell membranes [6].

In early infancy, asymptomatic carriage of $C$. difficile in the digestive tract is very common [7]. Many infants are colonized by toxigenic or non-toxigenic strains during the first two years of their life [8]. A study

Copyright: The authors. This article is an open access article licensed under the terms of the Creative Commons Attribution License (http://creativecommons.org/licenses/by/2.0) which permits unrestricted use, distribution and reproduction in any medium, provided the work is properly cited. was sparked by the finding of stool positive for $C$. difficile in two infants whose mortality was linked to sudden infant death syndrome (SIDS), showed significantly greater colonization in newborns fed on formula $(71 \%)$ than in breast-fed infants (7\%) [9].

Food animals were found to harbor $C$. difficile [10]. Moreover, it is transmitted from person to person via the fecal-oral route [11] and humans act as its natural reservoirs [12].

Owing to the incrimination of $C$. difficile in SIDS and because of very little information about its occurrence in the food, this study was aimed to detect whether toxigenic $C$. difficile occur in powdered infant and follow-up formulae.

\section{Materials and Methods}

The present study was carried out during April 2008-January 2010 in the Department of Food Hygiene, Faculty of Veterinary Medicine, Assiut University, Assiut, Egypt.

Collection of samples: A total of 100 random samples of powdered infant formula (PIF) and follow-up formula (FUF), 50 samples each, from different companies and different batches were collected from pharmacies and supermarkets in Assiut city. These samples were transferred to the laboratory in their packages for further examination.

\section{I solation of C. difficile [ 13]}

Enrichment of the samples: Margins of the can lids, scissors used for opening foil packages and spoons used for sampling were all properly sterilized prior to 
Table-1. Prevalence of $C$. difficile in powdered infant and follow-up formulae

\begin{tabular}{|c|c|c|}
\hline Examined samples & No. of examined & Positive samples \\
\hline Powdered infant formula & 50 & 8 \\
\hline Follow-up formula & 50 & 24 \\
\hline Total & 100 & 16 \\
\hline
\end{tabular}

withdrawing the samples.

Five grams of each sample were added to $20 \mathrm{ml}$ of C. difficile broth (CDB). The composition of CDB (per litre of medium) was proteose peptone $(40.0 \mathrm{~g})$, disodium hydrogen phosphate $(5.0 \mathrm{~g})$, potassium dihydrogen phosphate $(1.0 \mathrm{~g})$, magnesium sulphate $(0.1 \mathrm{~g})$, sodium chloride $(2.0 \mathrm{~g})$, fructose $(6.0 \mathrm{~g})$, sodium taurocholate $(1.0 \mathrm{~g})$, defibrinated horse blood (Oxoid SR50) $(50 \mathrm{ml})$ and $C$. difficile selective supplement (Oxoid SR96) (2vials). TWEEN 80 was added to the enrichment broth to improve the recovery of $C$. difficile [14]. CDB was incubated for 7 days at $37{ }^{\circ} \mathrm{C}$ under anaerobic conditions.

Selective plating: A loopful from the cultured broth was streaked onto Clostridium difficile agar media (Oxoid, CM 601) supplemented with cefoxitin and cycloserine (Oxoid $C$. difficile selective supplement, SR96) and 7\% defibrinated horse blood (Oxoid, Sr50). The plates were incubated anaerobically for $48 \mathrm{~h}$ at $37^{\circ} \mathrm{C}$.

I dentification of C. difficile [15]: Identification of $C$. difficile was by their colonial morphological criteria, Gram staining properties and odour. Colonies with a typical morphology (grey, flat, dry, spreading colonies) and/or a 'horse barn' odour were considered as suspicious for $C$. difficile. Suspected colonies were then subcultured on tryptone soya agar slopes (Oxoid CM 131) for further identification and toxin detection. Then isolates were tested for the common antigen of $C$. difficile using a latex agglutination test $(C$. difficile Agglutination Test Kit; Oxoid DR1107A, Basingstoke, UK).

Detection of toxigenic C. difficile [16]: The isolates that turned positive with latex agglutination technique were tested for the detection of $C$. difficile Toxin A and/or B using a rapid in vitro immunochromatographic test (Remel Xpect $C$. difficile Toxin A/B test kit; Oxoid $\mathrm{R} 24650)$. The test was performed according to the manufacturer's instructions. We dispensed $0.1 \mathrm{ml}$ of broth culture of suspected $C$. difficile into a dilution tube, added 5 drops of conjugate reagent 1 and conjugate reagent 2 to the dilution tube containing the broth culture, mixed the contents of the tube thoroughly and dispensed $0.2 \mathrm{ml}$ from the diluted mixture into the circular sample well of the test device. We read and recorded the test results visually after 20 min. A positive result (presence of toxin A and/or B) is indicated by two black-colored lines of any intensity, one in the TEST region and one in the control (CTRL) region.
Table-2. Toxigenic type characterization of $C$. difficile isolates

\begin{tabular}{|c|c|c|c|}
\hline \multirow[t]{2}{*}{ Examined samples } & \multirow{2}{*}{$\begin{array}{l}\text { No. of examined } \\
\text { samples }\end{array}$} & \multicolumn{2}{|c|}{ Positive samples } \\
\hline & & No. & \\
\hline Powdered infant formula & 4 & 0 & 0 \\
\hline Follow-up formula & 12 & 2 & 16.67 \\
\hline Total & 16 & 2 & 12.5 \\
\hline
\end{tabular}

\section{Results and Discussion}

PIF is a breast-milk substitute specially manufactured to satisfy, by itself, the nutritional requirements of infants during the first few months of their life up to the introduction of appropriate complementary feeding [17]. FUF are defined as foods that are intended for use as liquid components of the weaning diets for infants from the $6^{\text {th }}$ month onwards and for young children [18]. Similar to PIF, FUF are non-sterile products. Thus, they may contain bacteria that can cause serious illnesses in infants.

C. difficile is a bacterium of ubiquitous nature whose spore producing ability renders it highly resistant to environmental and food productionassociated stresses [19]. Recent studies have isolated C. difficile from retail foods intended for human consumption in Canada [13, 20], USA [21] and Europe [14,22]. These findings support concerns about foodborne acquisition of this pathogen through consumption or handling of the contaminated products [23]. However, until now there are no documented cases of $C$. difficile infections that resulted from eating food containing this bacterium [24].

The results in Table- 1 show that 4 (8\%) out of 50 examined PIF samples were positive for $C$. difficile, while, the prevalence of this organism in the examined FUF samples was $12(24 \%)$ out of 50 samples. The summarized results in Table 1 indicate that 16 out of $100(16 \%)$ examined samples of PIF and FUF were contaminated with $C$. difficile. The presence of $C$. difficile in PIF and FUF could result from environmental contamination or during handling.

Toxin studies have long been recommended for the diagnosis $C$. difficile which is the major cause of nosocomial diarrhea [25] and is the primary pathogen responsible for pseudomembranous colitis. Specifically, the rates of carriage of $C$. difficile and its toxins are high (50\% or more) in neonates [26].

Results summarized in Table-2 reveal that 2 (16.67\%) strains of the isolated $C$. difficile from the examined FUF were toxin positive; however, the isolated strains of $C$. difficile from the examined PIF samples were toxin negative.

Studies comparing human and animal $C$. difficile isolates (including isolates from foods of animal origin) suggest that animal reservoirs and transmission via foods of animal origin are the most likely sources for human illnesses [27].

It is interesting to note that majority of cases of $C$. difficile infection have been attributed to the occurrence of toxigenic strains. Studies showed that toxigenic strains are virulent and even if they do not 
exist, they may evolve over a period [1]. Consequently, it is important that both toxins A and B continue to be considered in the routine diagnosis and for the development of effective counter measures against $C$. difficile.

\section{Conclusion}

The presence of $C$. difficile in PIF and FUF samples suggests that there is a potential for transmission of $C$. difficile through these products. We thus recommend that proper precautions need to be taken during the preparation and handling to reduce the risk of illnesses arising due to the presence of $C$. difficile in PIF and FUF products.

\section{Authors' contributions}

NMS and WFA conceived and designed the study. EMS collected and analyzed the samples. EMS drafted and revised the manuscript. All authors read and approved the final manuscript.

\section{Acknowledgments}

Authors are grateful for the help provided by all members of the Department of Food Hygiene, Faculty of Veterinary Medicine, Sohag University, Sohag, Egypt.

\section{Competing interests}

The authors declare that they have no competing interests.

\section{References}

1. American Academy of Pediatrics (2013) Clostridium difficile Infection in Infants and Children. Committee on infectious diseases at: http://pediatrics. aappublications. org/content/131/1/ 196.full.html. Accessed on 25-06-2013.

2. Kuijper, E.J., Coignard, B. and Tull, P. (2006) Emergence of Clostridium difficile associated disease in North America and Europe. Clin. Microbiol. Infect. 12 (Suppl. 6): 2-18.

3. Gerding, D.N. (1989) Diseases associated with Clostridium difficile infection. Ann. Intern. Med. 110: 255-257.

4. Knoop, F.C., Owens, M and, Crocker, I.C. (1993) Clostridium difficile: Clinical disease and diagnosis. Clin. Microbiol. Rev. 6(3): 251-265.

5. Giannasca, P.J. and Warny, M. (2004) Active and passive immunization against Clostridium difficile diarrhoea and colitis. Vaccine Journal. 22(7): 848-856.

6. Kelly, C.P., Pothoulakis, C. and LaMont, J.T. (1994) Clostridium difficile colitis. N. Engl. J. Med. 330: 257-262.

7. Rousseau, C., Poilane, I., Pontual, L.D., Maherault, A., Le Monnier, A., Collignon, A. (2012) Clostridium difficile carriage in healthy infants in the community: A potential reservoir for pathogenic strains. Clin. Infect. Dis. 10: 1093.

8. Collignon, A., Ticchi, L., Depitre, C., Gaudelus, J., Delmee, M .and Corthier, G. (1993) Heterogenecity of Clostridium difficile isolates from infants. Eur. J. Pediat. 152:319-322.

9. Cooperstock, M.S., Steffen, E., Yolken, R. and Onderdonk, A. (1982) Clostridium difficile in normal infants and sudden infant death syndrome: an association with infant formula feeding. Pediatrics 70 (1): 91-95.
10. Simango, C. (2006) Prevalence of Clostridium difficile in the environment in a rural community in Zimbabwe. Trans. R. Soc. Trop. Med. Hyg. 100: 1146-1150.

11. McFree, R.B. and Abdel Sayed, G.G. (2009) Clostridium difficile. Dis. Mon. 55 (7): 449-470.

12. Kim, J.W., Lee, K.L., Jeong, J.B., Kim, B.G., Shin, S. and Kim, J.S. (2010) Proton pump inhibitors as a risk factor for recurrence of Clostridium difficile associated diarrhea. World J. Gastroenterol. 16 (28): 3573-3577.

13. Rodriguez-Palacios. A., Staempfli, H.R., Duffield, T..and Weese, J.S. (2007) Clostridium difficile in retail ground meat, Canada. Emerg. Infect. Dis. 13: 485-487.

14. Jöbstl, M., Heuberger, S., Indra, A., Nepf, R., Köfer, J., Wagner, M. (2010) Clostridium difficile in raw products of animal origin. Int. J. Food Microbiol. 138: 172-175.

15. Indra, A., Lassnig, H., Baliko, N., Much, P., Fiedler, A., Huhulescu, S. and Allerberger, F. (2009) Clostridium difficile: a new zoonotic agent? Wiener klinische Wochenschrift 121:91-95.

16. Planche, T., Aghaizu, A., Holliman, R., Riley, P., Poloniecki, J., Breathnach, A. and Krishna, S. (2008) Diagnosis of Clostridium difficile infection by toxin detection kits: a systematic review. The Lancet Infec. Dis. 8 (12): 777-784.

17. CAC (Codex Alimentarius Commision) (1981) Codex standard for infant formula and formulas for special medical purposes intended for infants. Codex Stan 72-1981, Section A. Available at: http://www.codexalimentarius.org/input/ download/standards/288/CXS_072e.pdf. Accessed on 2306-2013.

18. CAC (Codex Alimentarius Commision) (1987) Codex standard for follow up formula. Codex Stan 156-1987. Available at: http://www.codexalimentarius.org/input/ download/standards/293/CXS_156e-pdf. Accessed on 2506-2013.

19. McFarland, L.V. (2002) What's lurking under the bed? Persistance and predominance of particular Clostridium difficile strains in a hospital and the potential role of environmental contamination. Infection Control and Hospital Epidemiology 23: 639-640.

20. Weese JS., Avery BP., Rousseau J., Reid-Smith RJ.(2009) Detection and enumeration of Clostridium difficile spores in retail beef and pork. Appl Environ Microbiol 75(15): 5009-5011.

21. Songer, I.G., Trinh, H.T., Killgore, G.E., Thompson, A.D., McDonald, I.G. and Limbago, B.M. (2009) Clostridium difficile in retail meat products, USA. Emerg. Infect. Dis. 15(5) 819-821.

22. Von Abercron SM, Karlsson F, Wigh GT, Wierup M, Krovacek K. (2009) Low occurrence of Clostridium difficile in retail ground meat in Sweden. J Food Prot 72(8): $1732-1734$.

23. Hannah GL. and Brandi L (2010) Clostridium difficile in Food and Domestic Animals: A New Foodborne Pathogen? Clinical Infectious Diseases 51(5):577-582.

24. De Boer, E., Zwartkruis-Nahuis, A., Heuvelink, A., Harmanus, C. and Kuijper, E. (2011) Prevalence of Clostridium difficile in retailed meat in The Netherlands. Int. J. Food Microbiol. 144(3): 561-564.

25. Johnson, S. and Gerding, D. (1998) Clostridium difficile associated diarrhea. Clin. Infect. Dis. 26:1027-1034.

26. Bartlett, J.G. (1997) Clostridium difficile infection. Pathophysiology and diagnosis. Semin. Gastrointest. Dis. 8: 12-21.

27. Rupnik, M. (2007) Is Clostridium difficile-associated infec $\neg$ tion a potentially zoonotic and foodborne disease? Clin. Microbiol. Infect. 13: 457-459. 